\title{
Constelações fílmicas: um método comparatista no cinema
}

\author{
Mariana Souto' \\ https://orcid.org/0000-0002-4914-2988 \\ I - Universidade de Brasília \\ Brasília (DF), Brasil
}

Resumo: Este artigo propõe debater e adensar os estudos comparativos no cinema, campo carente de sistematização. Informados pelas contribuições de autores e áreas distantes - de um lado, Walter Benjamin, de outro, a astronomia -, aventamos um método comparatista próprio: as constelações fílmicas. Um exemplo de constelação (os musicais trabalhistas) é demonstrado no intuito de exercitar essa metodologia de análise, que tem como característica uma grande abertura para a sensibilidade dos pesquisadores na experiência com as imagens. As constelações advêm da liberdade de estabelecer conexões entre partes dispersas, fundada em um pensamento que escapa ao linear e busca a criação de redes entre filmes.

Palavras-chave: constelação fílmica; metodologia; cinema comparado.

Abstract: Film constellations: a comparative method in cinema - This article discusses the comparative studies in cinema, a field lacking systematization. Informed by the contributions of authors and distant areas - on the one hand, Walter Benjamin, on the other, astronomy - we propose our own method: the film constellations. One example of constellation is demonstrated in order to exercise this methodology of analysis which has as characteristic a great opening for the sensitivity of the researchers in the experience with images. With freedom to establish connections between dispersed parts, constellations are based on a non-linear thought which seeks to create networks between films.

Keywords: film constellation; methodology; comparative cinema.

Este artigo propõe debater e adensar os estudos comparatistas no cinema, âmbito carente de sistematização, em especial na língua portuguesa. Trata-se de abordagem utilizada frequentemente por pesquisadores que procedem a suas análises simultâneas de dois ou mais filmes, contudo poucas vezes expondo e problematizando o próprio método. É preciso investigar as possibilidades de associação entre obras, testar a empregabilidade 
dos métodos e explicitar caminhos que, por mais que sejam produtivos, muitas vezes são percorridos de forma irrefletida. A comparação se mostra pertinente quando o objetivo é, mais do que se deter sobre traços verticais das obras, apreender a dinâmica e as conexões entre elas. Como são múltiplos os modos de agrupamento, combinações e pareamentos entre filmes, muitas são as vertentes comparatistas que poderíamos pesquisar, como inventário, coleção, série histórica, comparação prismática (SILVA, 2009) e constelação. Nos limites deste artigo, é esta última que acolhe nosso esforço de definição e estruturação.

Partimos da premissa de que a conformação de um corpus e a maneira de abordá-lo é um momento fundamental no contexto de uma pesquisa, sendo preciso elaborar percursos especiais para seguir essa empreitada. Propomos injetar na dinâmica metodológica algo de vivacidade ao ver os objetos como interagentes entre si, tecendo relações de afinidade, estranhamento, amizade, semelhança e diferença - ora estimulados pelos pesquisadores, ora de maneira independente de suas ações. Partimos do pressuposto de que os filmes são como substâncias que, só quando aproximadas, saberemos como se comportarão: uns se fundem, outros se repelem como água e óleo; uns explodem ao contato, outros mudam de estado físico; e há ainda os que não reagem. Como obras que se atualizam a cada novo confronto com a imaginação e a memória de seu espectador, os filmes são objetos vivos cujas ideias variam ao sabor do tempo e do espaço sem, todavia, abdicar de sua autonomia no mundo. Assim, tão importante quanto a relação dos pesquisadores com os objetos é a relação que produzimos dos objetos entre si. É preciso relacioná-los e desenvolver cotejos entre eles, colocando-os em movimento. Desse modo, praticamos uma perspectiva de investigação que se permita ser guiada pela força da empiria e que tenha como princípio a observação e a escuta atentas dos objetos. Os filmes - e os agrupamentos que constituem - têm o poder de despertar inquietações, engendrar perguntas e provocar caminhos.

\section{Constelações benjaminianas}

Constelações estão presentes, de modo figurado e alegórico, em campos do conhecimento como filosofia e história. Em nossa pesquisa bibliográfica, no entanto, muitas vezes nos deparamos com o termo "constelação" tomado sem rigidez ou densidade conceitual, usado no senso comum simplesmente como sinônimo de conjunto ou grupo. O que propomos é cavar um caminho de solidez e especificidade em que o termo "constelação", não cabendo a qualquer agrupamento de filmes, será adotado quando seguidos alguns preceitos.

A noção está disseminada por algumas obras de Walter Benjamin, dos primeiros aos últimos escritos, especialmente em Origem do drama barroco alemão (1984) e as teses Sobre o conceito da História (1996), mas, na maioria das vezes, aparece de maneira breve, furtiva, nem sempre como conceito e mais como uma alusão metafórica empregada no 
sentido de clarear outras ideias. É curioso notar que comentadores(as) utilizam mais o termo do que o próprio Benjamin. Dificulta, ainda, o fato de que "constelação" (Konstellation) por vezes aparece traduzido para o português como "configuração", achatando a especificidade da proposta e dando à expressão um aspecto fugidio qualquer. Sérgio Paulo Rouanet, seu principal tradutor no Brasil, muitas vezes utiliza um termo pelo outro, como se fossem sinônimos - Georg Otte e Miriam Volpe esclarecem:

\begin{abstract}
Assim, Benjamin retraduz o latinismo Konstellation para o alemão Sternbild, 'imagem de estrelas', expressão esta que se caracteriza por um maior grau de transparência. Não se trataria apenas de um conjunto (constelação), mas de uma imagem, o que significa, em primeiro lugar, que a relação entre seus componentes, as estrelas, não seja apenas motivada pela proximidade entre elas, mas também pela possibilidade de significado que lhes pode ser atribuída (OTTE; VOLPE, 2000, p. 37).
\end{abstract}

Um passo atrás será necessário para compreender como a noção de constelação se insere na obra desse autor. Walter Benjamin acreditava numa concepção não homogênea de tempo e criticava o entendimento da história como um processo linear, progressivo, de adição de fatos. Sua posição, a de uma histografia materialista, rompe com a ideia de continuidade. Diferente de um registro linear e da exposição lógica da história, ele propõe uma apresentação fragmentária e pictórica. Adepto dos métodos de montagem e de mosaico com o objetivo do choque, do estranhamento e da desnaturalização, Benjamin parece ter um raciocínio que valoriza o visual, a ótica, muitas vezes buscando por imagens. Ao invés de uma atitude passiva de quem assiste a história se desenrolar, ele propõe o engajamento na formação de constelações: seu objetivo deve ser descobrir uma constelação crítica que um momento do passado forma com o presente (LÖWY, 2005). Letícia Botelho (2012) explica que uma constelação lampeja diante do crítico "quando dois fenômenos, cronologicamente distantes e aparentemente heterogêneos, colocados em cotejo entre si, iluminam-se reciprocamente, revelando certa afinidade interna" (BOTELHO, 2012, p. 108). Michael Löwy (2005) aponta que esse encontro entre tempos produz ganhos recíprocos: "a relação entre hoje e ontem não é unilateral: em um processo eminentemente dialético, o presente ilumina o passado, e o passado iluminado torna-se uma força no presente" (LOWY, 2005, p. 61). Assim, a constelação pode historicizar um fato ou objeto do presente à luz de seus diálogos com possíveis antepassados.

Para que isso aconteça, é preciso deter-se por um momento, interromper o fluir do tempo. Diante de fatos que possuem algum tipo de relação, sejam próximos ou separados por séculos, cabe fazer uma pausa, produzir uma espécie de congelamento. É como um intervalo para um trabalho de restauração em que se coletam vestígios, fragmentos de um elo perdido. 
Contrariando a perspectiva teleológica, Benjamin valoriza o presente por ser o momento da imobilização da história, do "choque" que interrompe seu fluxo contínuo, possibilitando que os elementos, que, devido à ótica linear do tempo, foram afastados uns dos outros, se aproximem novamente numa imagem: "imagem é aquilo onde, à maneira de um relâmpago, o acontecido se une ao agora numa constelação" (BENJAMIN apud OTTE; VOLPE, 2000, p. 42).

A relação de um determinado fato do passado com o presente não é uma sucessão dada ou óbvia, mas emerge de um trabalho de detecção que encontra uma imagem que salta, carregada de tensões, com potencial explosivo. Rememorar tem como tarefa a criação dessas constelações que fazem uma ligação privilegiada entre tempos - ligação essa que não é da ordem da causalidade, da filiação ou do progresso, mas de um "pacto secreto" (LÖWY, 2005). As constelações, momentos "arrancados da continuidade histórica vazia, são mônadas, ou seja, são concentrados da totalidade histórica" (LÖWY, 2005, p. 131). Theodor W. Adorno, que também alude às constelações, diz que "o conhecimento do objeto em sua constelação é o conhecimento do processo que ele acumula em si" (ADORNO, 2009, p. 142).

Metodologicamente, portanto, faz sentido olhar para a constelação como meio de se chegar a algo maior, a uma espécie de totalidade que ela cristaliza. Há, nela, uma historicidade interna, revelada a partir desse lampejo que se precipita pelo cotejo de dois ou mais ingredientes conectados por uma linha imaginária. Uma afinidade interior se revela. Se Löwy fala em "pacto secreto", a tarefa do crítico seria justamente produzir um vínculo entre elementos, ali camuflado entre tantos outros possíveis. A formação e o estudo da constelação trariam essa possibilidade de "abrir a história", para usar os termos de Benjamin. Adorno se aproxima da metáfora do segredo quando diz que o pensamento teórico, enquanto constelação, abre os conceitos que circunscreve "não apenas por meio de uma única chave ou de um único número, mas de uma combinação numérica" (ADORNO, 2009, p. 142). A constelação é dotada de múltiplos pontos dispostos no espaço que, somados, crescem em complexidade e funcionam como essa combinação numérica capaz de revelar algo por diversas frentes e perspectivas. Constelar é uma forma de produzir chaves de leitura, de produzir um sentido a partir de sua visão em uma teia de relações. O objeto se abre quando ganhamos consciência da constelação na qual se encontra.

A constelação tem, assim, um poder revelador de ajudar a produzir uma releitura, sendo capaz de inspirar o presente ou de trazer alguma espécie de redenção para os ocorridos do passado". Ela integra sua proposta de "escovar a história a contrapelo", dedicada à tentativa de reescritura de uma história opressora, que se conta sempre do ponto de vista dos grupos dominantes.

1 A vinculação desses tempos apartados, para Benjamin, é pautada pela experiência da derrota, pelo trauma dos vencidos e é despertada por um perigo iminente. A constelação teria, então, uma função redentora e revolucionária, funcionando como arma cultural para os combates do presente. Trata-se de um "campo de forças sombrio, de forma que o presente político possa redimir um momento doloroso do passado" (EAGLETON, 1993, p. 238). É preciso considerar o momento em que Benjamin escreve, sendo um judeu alemão vivendo a ascensão do nazismo, tão próximo da catástrofe, completamente absorvido por esse contexto. A constelação e seu uso contemporâneo, como a propomos no campo do cinema, não exige, necessariamente, um caráter tão fortemente revolucionário, ainda que não se deva desvinculá-la de uma perspectiva de reescrita e reorganização da história. 


\section{Constelações astronômicas}

Ainda que Benjamin e seus comentadores não tenham feito da constelação um conceito ou instrumento metodológico de fato, seu recurso ao vocabulário das estrelas nos abre um caminho instigante. Nesse sentido, parece-nos profícuo adentrar brevemente o campo da astronomia para desvendar alguns dos princípios que tanto atraíram o filósofo alemão.

Imaginemos uma cena de milênios atrás, antes do desenvolvimento da escrita, com grupos humanos reunidos à noite ao redor do fogo, admirando o firmamento. Os contadores de histórias usavam a paisagem celeste como ilustração de suas narrativas de deuses, feras e heróis, formando desenhos a partir da união dos pontos brilhantes. O céu funcionava, então, como uma grande tela de projeção para espectadores que imaginavam ver ali imagens dos personagens, animais e objetos narrados. Se os próprios desenhos inspiravam a criação de histórias ou se as histórias vinham antes e o contador buscava elementos no céu que as expressassem é parte do mistério dessa cena imaginada2. Essa cena pode ser tomada como uma alegoria do cinema, vinda de tempos tão longínquos (como o mito da caverna de Platão, ora apropriada com o mesmo propósito). A sensação de fascínio pelas imagens, a imersão na escuridão, os olhos voltados para a luz e a experiência coletiva já fazem parte dessas "narrativas audiovisuais" primordiais, pontos comuns com a vivência cinematográfica até os dias de hoje.

O vínculo entre áreas tão distintas quanto astronomia e cinema é produtivo não em termos literais, mas pelo auxílio retórico, discursivo e fabulativo que nos fornece na elaboração de um pensamento. Embora a ideia da constelação demonstre afinidade com o cinema no contexto das teorias de dispositivo, nosso intuito maior é aproximá-la de outro momento da pesquisa: a conformação de um corpus de análise. Apostamos que a livre inspiração no vocabulário da astronomia pode trazer certo arejamento às investigações audiovisuais e fornecer subsídios para a lida com uma quantidade plural de filmes.

As constelações emergem de uma concepção relacional, que vê diálogos, tensões e afinidades entre as obras/estrelas, ainda que essa conversa não tenha sido por elas planejada. Afinal, não se trata de vínculo dado na natureza, preexistente - quem faz a ligação entre os pontos é o observador. Constelações são agrupamentos imaginários de estrelas. Elas se constituem pelo olhar humano localizado, a partir de um determinado ângulo de observação, tendo como base suas próprias projeções mentais e seu repertório de objetos conhecidos. São uma questão de perspectiva. As estrelas de uma constelação não possuem nenhum vínculo real, muitas vezes estão mais distantes entre si do que de outras estrelas que não pertencem àquele desenho. Não estão juntas, não há uma força gravitacional que as una - para esse tipo de agrupamento há um outro nome: "aglomerado estelar" designa as estrelas fisicamente relacionadas, que se movem pela galáxia na mesma direção e velocidade. Já as constelações não são fenômenos reais,

2 A descrição dessa cena é inspirada por uma palestra do cientista britânico lan Ridpath, especialista em astronomia, gravada na The Royal Society em Londres (2010). 
mas uma produção humana, uma abstração. "São todas falsas, deliciosamente falsas, essas constelações. Unem, numa mesma figura, astros totalmente estranhos. Entre pontos reais, entre estrelas isoladas qual diamantes solitários, o sonho constelante traça linhas imaginárias" (BACHELARD, 1990, p. 179).

Esse pensamento, transposto para a pesquisa em cinema, permite-nos uma maior liberdade na escolha de filmes cujas relações são propostas pelo olhar mesmo que os aglutina e que não estão programadas de antemão. Assim, a aproximação entre obras pode escapar a critérios mais evidentes como a pertença às categorias usuais da comparação (gênero, realizador/a, país ou ano de produção), embora elas possam também ter alguma influência no recorte. O agrupamento pode se dar com a liberdade de quem mira o céu, vê uma infinidade de pontos e une aqueles que produzem uma imagem de interesse - o que não dispensa a tarefa de demonstrar aos outros observadores quais são os vínculos ali enxergados e o porquê dessas ligações. A participação da subjetividade não se dá sem algumas balizas e tampouco deve se traduzir em completa arbitrariedade.

Se, de um lado, as constelações resultam de liberdade e abstração, por outro, elas têm uma função de organização e ordenação. Em outras palavras, elas também ajudam na divisão do universo em porções menores, "administráveis", e são úteis na agricultura, na navegação e na criação de calendários. Da mesma forma, constelações no cinema, tal como as propomos aqui, oferecem algumas balizas e auxiliam o pesquisador a organizar e situar alguns pontos de destaque em meio a um panorama maior.

A respeito da dimensão temporal das constelações, convém saber que elas são formações provisórias. Justamente porque cada uma das estrelas está a distintas distâncias da Terra e se afasta em sua própria direção e velocidade, os desenhos estão sujeitos a mudanças ao longo do tempo, talvez mesmo a deformações e desaparecimentos, ainda que isso não aconteça na escala de uma vida humana. Os arranjos não são fixos e podem não mais fazer sentido no futuro.

Ao lado da variação temporal, há também uma variação espacial no sentido de que são percebidas e nomeadas de modo diverso por culturas ao redor do planeta. Ursa Maior é conhecida na França como Caçarola e na Inglaterra como Arado. Nossas constelações vieram majoritariamente dos gregos, enquanto culturas orientais percebem outros arranjos no céu. Os desenhos foram se multiplicando e variando ao longo do tempo. No século XVII, época das grandes navegações, holandeses produziram um catálogo com novas constelações, tais como pavão, tucano e camaleão - espécies que impressionavam o olhar europeu (RIDPATH, 2000). Eles estavam, portanto, simultaneamente explorando áreas desconhecidas da terra e do céu. Isso reafirma que "as constelações não são formações naturais, mas 'imagens culturais', diferentes segundo as épocas" (OTTE; VOLPE, 200, p. 39). Bachelard fala de uma certa "exuberância das forças da imaginação projetante" (BACHELARD, 1990, p. 179). 
Hoje, apenas 88 são consideradas constelações oficiais, resultado de uma convenção de 1930 da União Astronômica Internacional, que decidiu também que uma mesma estrela não pode fazer parte de mais de uma constelação, como era o caso de Beta Tauri, ao mesmo tempo a ponta do chifre de Touro e o pé do Cocheiro (Auriga). No entanto, essa sobreposição nos parece apropriada em termos fílmicos. Um mesmo filme pode participar de diferentes constelações, revelando nuances distintas a depender do grupo em que se insere.

\section{A constelação fílmica}

Depois da exposição dos apontamentos de teóricos como Benjamin, Adorno e seus comentadores e da visita às contribuições da astronomia, como pensar e operacionalizar as constelações no cinema? Nem o próprio Benjamin, em seus textos, fornece ilustrações ou exemplos, tornando difícil sua concretização. Aliás, a tarefa por ele imputada ao críticohistoriador de viés materialista é um trabalho e tanto, quase uma missão:

orientar-se, na crítica das obras de arte, pelos sofrimentos e esperanças frustradas dos vencidos, por sua experiência coletiva passada, de modo a expor uma constelação redentora e revolucionária da história, intimamente relacionada à transformação do presente e do próprio passado (BOTELHO, 2012, p. 116).

Para Benjamin, as constelações exigem um propósito revolucionário e redentor, pertinente ao contexto em que foram pensadas. Aquilo que chamaremos de "constelações fílmicas" (também permeáveis a produções de outras ordens, como pintura e fotografia) pretende manter o potencial crítico das constelações de Benjamin, mas aceita que este potencial eventualmente se manifeste de formas distintas das que ele anteviu ${ }^{3}$. Sem propor um afastamento das ideias do autor, que nos são caras, esta seria uma maneira de mantêlo como inspiração e referência, mas também de preservar a autonomia da pesquisa, considerando as especificidades de um tempo e de uma área.

Ainda que não seja propriamente "revolucionária", a constelação fílmica, sendo tensionadora e imaginativa, será, em certo sentido, crítica. A própria lógica anacrônica e desnaturalizadora que reúne obras já carrega uma fagulha de tensão e um convite à reconfiguração de elementos do mundo sensível. Propomos também uma flexibilidade temporal na lida com os objetos. Susan Buck-Morss aponta que Adorno, influenciado por Benjamin,

estava menos preocupado com a possibilidade de documentar uma conexão entre um acontecimento anterior e um mais recente (embora ele fizesse isso quando possível), e mais preocupado com arquétipos históricos, protótipos para a estrutura de fenômenos presentes (BUCK-MORSS, 1979, p. 259).

3 Sintonizando o pensamento de Benjamin com nosso tempo, podemos dialogar com as concepções políticas mais contemporâneas de autores como Michel Foucault e Jacques Rancière, por exemplo. 
O interesse de Adorno era pela montagem de uma constelação que pudesse revelar o aparecimento de algo na história de maneira a decifrar o presente. A construção de uma constelação é sempre "mediada pelo presente histórico, o ponto de referência de todo conhecimento" (BUCK-MORSS, 1979, p. 263). Uma constelação deve lidar fundamentalmente com uma noção de historicidade, mas de maneira mais abrangente isto é, considerar o aspecto da historicidade não significa que ela deva, necessariamente, unir filmes com datas de produção distantes. Benjamin coloca como intenção "desfazer e refazer conexões, a partir da constituição de um novo - e, não raro, inesperado - plexo de referências" (BRETAS, 2008, p. 179-180). Para nós, o que caracteriza a constelação é a "liberdade de estabelecer ligações entre partes dispersas" (OTTE; VOLPE, 2000, p. 39). Daí propomos que as constelações fílmicas devem também quebrar encadeamentos causais tidos como dados, questionar relações já gastas que talvez tenham perdido seu poder explicativo, furar a fila da continuidade histórica, não mais traçar da esquerda para a direita, em uma reta linha do tempo, mas unir pontos transversalmente, sair do plano bidimensional e usar também a dimensão da profundidade.

Um par não faz constelação, que só se forma a partir de um mínimo de três obras como nas Três Marias. Essa premissa não é arbitrária, mas é importante para o raciocínio constelacional, que não pode se forjar apenas no ponto-contraponto. A triangulação é fundamental para o fomento de um pensamento que escapa ao linear.

No estudo constelacional, não se trata de simplesmente duplicar, triplicar ou quadruplicar o que se faria com um único filme e repetir os procedimentos conforme o número de obras analisadas (como num modelo pesquisador-filme $A$, pesquisador-filme B, pesquisador-filme C), mas de questionar também as relações entre os filmes A, B e C. Trata-se de subverter esse lugar do pesquisador como centro irradiador de vínculos sempre lineares e consecutivos e, ao invés disso, triangular mais as relações ou experimentar formatos de outras geometrias - dos desenhos mais conhecidos até aqueles que possam ser forjados ao longo da pesquisa, complexos, imprevisíveis, mutantes. As constelações podem estender do passado caminhos distintos no presente, formando bifurcações, ou podem dar conta das distâncias e proximidades entre os filmes, mostrando, por exemplo, em um conjunto de cinco, que determinado par de filmes está mais próximo entre si do que de um outro trio de obras.

Em termos metodológicos, convém pensar que "a constelação é simultaneamente procedimento e composição" (SILVA; AZEREDO; BITTENCOURT, 2016, p. 283), o que ressalta a importância do processo de constelar, e não apenas seu resultado, como interesse de pesquisa. A constelação é a cristalização de um trajeto de pensamento e carrega em si um trabalho. Não é só conteúdo, mas modo de ordenação e exposição - o que certamente também envolve reflexão. Quando pronta, traz as marcas de um percurso. A constelação não é exatamente uma coisa, mas uma proposta de relação. 
Assim, importa pensar a disposição dos filmes na constelação, percebendo o tamanho que cada obra ocupa no conjunto e sua relevância no todo. É crucial atentar não apenas para os pontos, mas também para os intervalos entre eles, as articulações, as distâncias. O entendimento de como as obras se relacionam, a proposta dos vínculos e sua representação visual na pesquisa exigem do pesquisador uma certa capacidade de tradução imagética de suas ideias. Nesse caso, "pesquisar por meio de imagens também pressupõe dizer por meio de imagens" (SANTOS, 2017, p. 150). No entanto, não são ideias que estão prontas mentalmente carecendo apenas de uma materialização no papel, mas são aquelas que podem aparecer ou se ajustar nesse processo, na feitura de croquis e rabiscos que ensaiam tentativas combinatórias. Combinações podem ser experimentadas até que uma se fixe, ainda que temporariamente. Como exemplo de diagramação de uma constelação, observemos a imagem abaixo (Fig. 1):

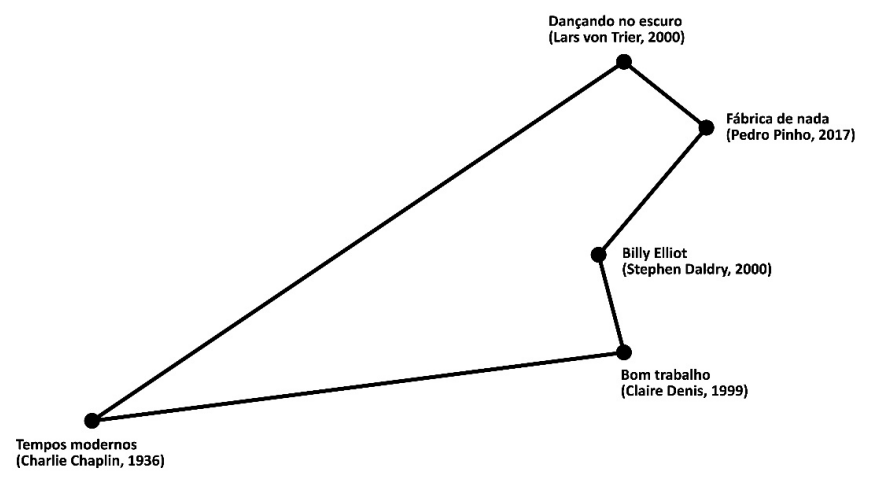

Fig. 1. Constelação dos musicais trabalhistas ${ }^{4}$

A constelação faz rede, não linha. Se extrapolarmos o escopo de uma análise e trabalharmos com conjuntos de constelações, vinculados por pontos de interseção, chegamos a um panorama que podemos chamar de galáxias: "a constelação amplia-se a galáxias, vira universo, infinito" (SANTOS, 2017, p. 133). É uma expansão que se dá tridimensionalmente. Uma galáxia pode abarcar diversas constelações.

O objetivo do método que estamos construindo não é simplesmente detectar recorrências e fazer disso uma coleção de gestos, como se a percepção dessas repetições imprevistas fosse suficiente para coroar a pesquisa - embora essa possa ser uma etapa fundamental para se reconhecer uma tendência ou um movimento mais transversal. A comparação na constelação não é simplesmente icônica. Do álbum de rimas, que gera

4 Esse artigo dedica sua atenção à dimensão teórico-metodológica, de modo que a apresentação e análise dessa constelação, será desenvolvida em outra publicação. 
a aparente saciedade oriunda da impressão de "incrível semelhança", é preciso avançar a reflexão. As imagens, portanto, não surgem numa condição ilustrativa e nem são ponto de chegada, mas devem ajudar a construir e estruturar a reflexão. Pensamos com as imagens, através das imagens.

A constelação pode colocar em comparação frames de filmes variados, mas também trabalhar com elementos menos palpáveis, que não se concentram nem se isolam numa única imagem. Como breve exercício metodológico para demonstrar minimamente as aplicações possíveis do método constelatório, descreveremos o caminho de formação de uma constelação.

No português A fábrica de nada (PEDRO PINHO, 2017), operários à beira da demissão em massa ocupam uma fábrica de elevadores. O filme se constrói na heterogeneidade, mesclando ficção e documentário, inserindo não atores, intercalando discussões na fábrica com outras entre intelectuais. Em dado momento, o telefone toca. É uma grande encomenda, a promessa de trabalho e dinheiro. Os operários se põem a cantar e dançar e quebram a encenação quase neorrealista que se vinha erigindo.

No longo número musical que toma conta da cena, personagens uniformizados dançam coreografias, formam círculos concêntricos e cantarolam. São pessoas de meiaidade, algumas grisalhas, sem destreza ou voz notáveis para uma performance dessa natureza. A sequência se encerra com a revelação de que teria sido uma encenação dirigida por um personagem do filme, uma figura ambígua entre intelectual e cineasta, que se aproxima daquele movimento trabalhista com sua própria agenda. Da expressão da pura alegria, passamos a entender aquela dança como uma manipulação, em que os trabalhadores estariam ali como fantoches de uma representação. Toda a sequência musical acontece a $2 \mathrm{~h} 25$ de um filme cuja duração é de $3 \mathrm{~h}$, tomando os espectadores de assalto. Ela não mais se repete. Diante da experiência de espanto gerada pelo filme, algumas perguntas começaram a despontar: como se dá essa intensa e desconcertante quebra no filme? A que serve o musical nesse contexto?

Apesar da distância temporal e estética, as cenas musicais no chão da fábrica ativaram a memória de Dançando no escuro (LARS VON TRIER, 2000). Quem sabe visitando esse filme com as inquietações do primeiro conseguiríamos responder a algumas perguntas ou, ao menos, lançar perguntas novas, estender o debate e ampliar o conhecimento em torno da questão. As cenas em que a personagem de Björk, guiada pelo estímulo dos ruídos ritmados das engrenagens, vislumbra um mundo menos opressor e mais fantasioso deixou por sua vez uma pista para retornarmos a Tempos modernos (CHARLES CHAPLIN, 1936). Nele também vimos um personagem dançar conforme a música da máquina, seus movimentos repetitivos extrapolando a linha de montagem. Ali, a dança parece vir da exaustão, que leva a um "colapso nervoso", como diz a cartela do filme. O corpo indócil entra em pane, sabota o sistema e dança. Chaplin aperta parafusos no ar, desloca-se saltitante no espaço, perseguido pelos personagens repressores. A catarse da dança pode ainda nos remeter, 
por via mais indireta, a Bom trabalho (CLAIRE DENIS, 1999), em que o treinamento dos soldados e a minuciosa observação do movimento ao mesmo tempo firme e lânguido de seus corpos produz uma insinuação de dança. Essa insinuação se concretiza na cena final, em que Denis Lavant (que interpreta o Sargento Galoup), sucumbe aos movimentos espasmódicos de seu corpo em uma discoteca, parecendo querer liberar toda a tensão erótica reprimida ao longo do filme. Esse encerramento possivelmente alegoriza o suicídio do personagem, depois de afastado do exército pela expulsão de um soldado por quem sentia atração. A relação complexa entre dança e masculinidade nos leva a Billy Elliot (STEPHEN DALDRY, 2000), em que o personagem título escapa do destino de operário, ofício de seu pai e do irmão mais velho (em greve naquele momento), pela via da dança - Billy, para desgosto de sua família, dedica-se ao balé. Trata-se de um corpo dissidente no universo dos mineiros ingleses, que descreve a sensação de dançar como se tivesse sido tomado por "eletricidade". A dança figura como a manifestação de uma energia, não tão diferente da energia elétrica gerada a partir do carvão. Esse deslizamento entre filmes seria o ponto de partida da constelação que poderíamos batizar, com alguma graça, de "musicais trabalhistas". São filmes reunidos por um critério de liberdade, escapando aos eixos mais usuais da comparação (cineasta, país etc.). Não se trata tampouco de um agrupamento temático, pois a dança não é tema dos filmes e o musical não é exatamente seu gênero (talvez à exceção de Dançando no escuro), mas uma forma expressiva que deles se apodera em momentos pontuais. A dança, ao contrário do que se poderia supor, não romantiza nem embeleza o trabalho, mas insere uma dimensão de melancolia e crítica à sua representação.

Como eixo, temos a ideia de dança estreitamente conectada ao universo do trabalho (seja ele fabril ou militar), mas que aparece de maneiras profundamente diferentes a cada filme: ligada à euforia ou à manipulação ( $A$ fábrica de nada), ao escapismo de um trabalho duro (Dançando no escuro), ao esforço repetitivo e frenético no auge do capitalismo industrial (Tempos modernos), à catarse da repressão do ordenamento dos corpos masculinos (Bom trabalho), ao desvio inesperado de um corpo programado para o trabalho braçal (Billy Elliot). Constitui-se, portanto, uma constelação que parte de um eixo, mas que se funda essencialmente na diferença, como se ela pudesse nos auxiliar a enxergar melhor cada filme em sua singularidade.

A constelação está apenas anunciada nessas breves palavras; daí partiríamos efetivamente para a análise. Mas já é possível ver que não se trata de um agrupamento qualquer, mas de uma constelação que historiciza, que critica, formada pelas "forças da imaginação projetante" da pesquisadora diante de obras que parecem relacionáveis a partir de um "pacto secreto". Importa perceber como sua constituição coloca itinerários e pontos-chave para a investigação. 


\section{Considerações finais}

Através do método comparatista, a aproximação de filmes dá forças a impressões ainda indefinidas, fazendo com que se tornem cada vez mais vívidas e decisivas, auxiliando-nos a delinear tendências e conceitos. As constelações parecem ajudar a dar corpo e robustez a essas intuições, quando pertinentes. A reiteração de elementos confirma as hipóteses iniciais e sua variação em diferentes filmes fornece nuance às análises, já que não buscamos apenas as semelhanças, mas também as diferenças entre os filmes e suas particularidades.

Ao perceber certo traço significativo em um filme, vamos ao outro com um olhar mais atento a determinada questão. No contraste, a visão se apura. A memória de uma percepção funciona como instrumento de abordagem no contato com o próximo: um filme é a ferramenta de análise de outro. E aí, numa nova rodada, podemos voltar ao primeiro com um olhar a cada vez mais informado. Como a constelação não é linear, percorremos caminhos de ida e volta diversas vezes, sem ordem programada - tal como numa conversação. Um filme se expande em possibilidades interpretativas na relação com outras obras.

Com as constelações, esperamos contribuir para amenizar a sensação de escassez de material bibliográfico que tenha como foco apresentar algumas metodologias de análise audiovisual comparatistas e que pudesse mesmo servir como norte para os estudantes e pesquisadores em seus projetos. Se, por um lado, esperamos oferecer mais solidez a um método muitas vezes empregado de maneira intuitiva, também esperamos insuflar criatividade nos estudos acadêmicos, estimulando a cinefilia e a colocação de obras em relações de alteridade com outros textos.

Mariana Souto é professora na Faculdade de Comunicação da Universidade de Brasília (UnB). Doutora pela UFMG com pós-doutorado na Escola de Comunicações e Artes da Universidade de São Paulo (ECA-USP) com bolsa FAPESP.

marianasouto@gmail.com

\section{Referências}

ADORNO, T. W.; SILVA, E. S. N. Dialética Negativa. Rio de Janeiro: J. Zahar, 2009.

AUMONT, J. Pour un cinéma comparé: influences et repétition. Paris: Cinemathèque Française, 1996.

BACHELARD, G. O ar e os sonhos: ensaio sobre a imaginação do movimento. São Paulo: Martins Fontes, 1990. 
BENJAMIN, W. Magia e técnica, arte e política: ensaios sobre literatura e história da cultura. 3a ed. São Paulo: Brasiliense, 1987.

Origem do drama barroco alemão. São Paulo: Brasiliense, 1984.

. Passagens. Belo Horizonte: Editora UFMG, 2007.

BOTELHO, L. Walter Benjamin e as imagens da história - Possibilidades de uma crítica social a partir da arte. Pólemos, Brasília, vol. 1, n. 1, p. 104-122, 2012.

BRETAS, A. A constelação do sonho em Walter Benjamin. São Paulo: Humanitas, 2008.

BUCK-MORSS, S. The origin of negative dialectics: Theodor W. Adorno, Walter Benjamin, and the Frankfurt Institute. New York: The Free Press, 1979.

EAGLETON, T.; COSTA, M. S. R. A ideologia da estética. Rio de Janeiro: J. Zahar, 1993.

LÖWY, M. Walter Benjamin: aviso de incêndio. Uma leitura das teses 'Sobre o conceito de história'. São Paulo: Boitempo, 2005.

LUCAS, G. Editorial. Proyección/Montaje. Cinema Comparative Cinema, n.1, 2012, p. 7-8.

OTTE, G.; VOLPE, M. Um olhar constelar sobre o pensamento de Walter Benjamin. Fragmentos, Florianópolis, n. 18, p. 35-47, 2000.

SANTOS, D. Entre montagens e constelações: um estudo sobre a mobilidade das imagens. 2017. Dissertação (Mestrado em Tecnologia da Arquitetura) - Faculdade de Arquitetura e Urbanismo, Universidade de São Paulo, São Paulo, 2017.

SILVA, A.; AZEREDO, J.; BITTENCOURT, R. O pensamento em constelação adorniano como possibilidade de reflexão crítica sobre as práticas formativas em contextos educativos. Conjectura: Filos. Educ., Caxias do Sul, v. 21, n. 2, p. 275-287, maio/ago. 2016

SILVA, M. A. Jean Rouch e Glauber Rocha, de um transe a outro. In: Revista Devires: cinema e humanidades. Belo Horizonte, V. 6, N. 1, p. 40-73, jan-jun-2009.

XAVIER, I. O olhar e a cena: melodrama, Hollywood, cinema novo, Nelson Rodrigues. São Paulo: Cosac \& Naify, 2003.

. Sertão mar: Glauber Rocha e a estética da fome. São Paulo: Cosac \& Naify, 2007.

Artigo recebido em 31/08/2019

e aprovado em 27/10/2019. 